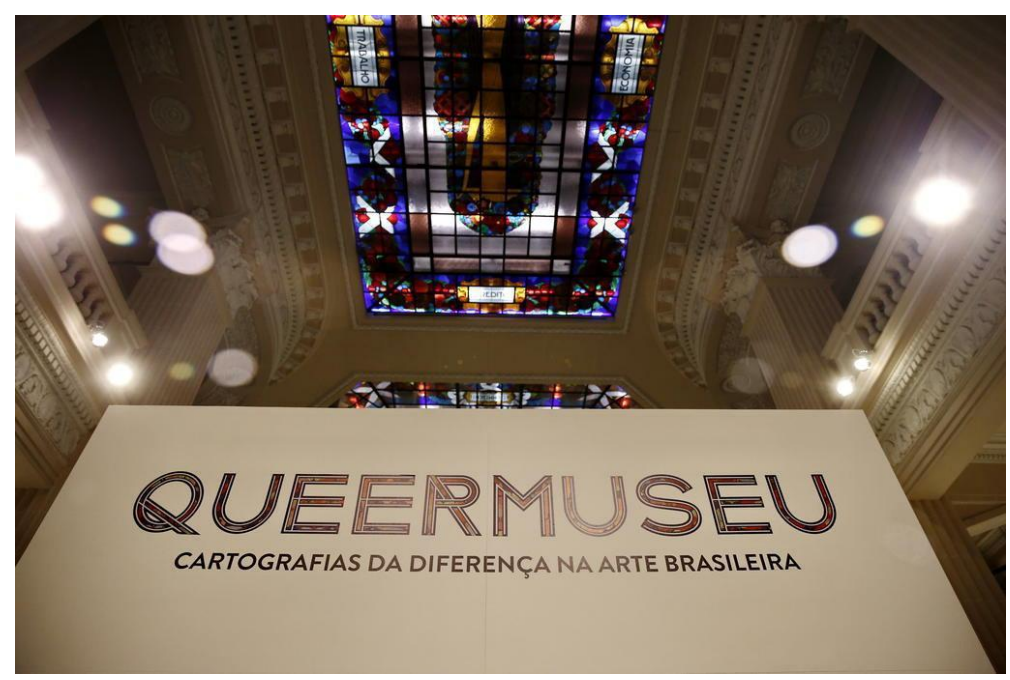

\title{
A estética da intolerância: extremismo político e arte no Brasil atual
}

The aesthetics of intolerance: political extremism and art in Brazil today

\author{
Argus Romero Abreu de Morais ${ }^{1}$ \\ https://orcid.org/0000-0002-3606-110X
}

\section{Resumo:}

No presente trabalho, debateremos a relação entre arte e política na reação à Mostra Queermuseu. Partindo das contribuições de Pêcheux (2009), aproximaremos as investigações de Barros (2007), Eco (1995), Oz (2016) e Paxton (2007) sobre os conceitos de intolerância, fascismo universal, fanatismo e fascismo dos conceitos de ideologia em Hall (2007), de jogos de linguagem em Wittgenstein (2009), de ralé em Arendt (2012) e de direita política em Cruz (2015) para definir a categoria de extrema-direita brasileira na atualidade e sugerir a categoria de estética da intolerância. Para tanto, avaliaremos os textos de Júnior (2017) e de Santos (2017) e a moção de repúdio da Câmara de Vereadores de Uruguaiana à Exposição (CÂMARAMUNICIPAL, 2017). Palavras-chave: Estética. Intolerância. Extremismo político. Arte.

\begin{abstract}
:
In the present work, we will discuss the relationship between art and politics in the reaction to the Mostra Queermuseu. Based on the contributions of Pêcheux (2009), we will approach Barros (2007), Eco (1995), Oz (2016) and Paxton (2007) on the concepts of intolerance, ur-fascism, fanaticism and fascism of the concepts of ideology in Hall (2007), language-game in Wittgenstein (2009), mob in Arendt (2012) and political right in Cruz (2015) to define the category of Brazilian far-right nowadays and suggest the category of aesthetics of intolerance. To do so, we will evaluate the texts of Júnior (2017) and Santos (2017) and the motion of repudiation of the City Council of Uruguaiana to the Exhibition (CÂMARAMUNICIPAL, 2017).
\end{abstract}

Keywords: Aesthetics. Intolerance. Political extremism. Art.

\footnotetext{
${ }^{1}$ Professor colaborador do Programa de Pós-Graduação em Letras: Cultura, Educação e Linguagens da Universidade Estadual do Sudoeste da Bahia (PPGCEL/UESB) e pós-doutorando (PNPD/CAPES) no Programa de Pós-Graduação em Letras: Teoria Literária e Crítica da Cultura da Universidade Federal de São João del-Rei (PROMEL/UFSJ), Campus Dom Bosco. Email: argusromero@ yahoo.com.br
} 


\section{Considerações iniciais}

Partindo do enquadramento geral do problema da intolerância na sociedade brasileira contemporânea, no presente texto, tentaremos discutir a relação entre extremismo político e arte hoje, especificamente, a partir da reação à Exposição Queermuseu, em Porto Alegre/RS, em setembro de 2017. Nesse intuito, valendo-nos do escopo teórico-metodológico da vertente pecheutiana da Análise do Discurso (PÊCHEUX, 2009) e da proposta teórico-metodológica de Morais (2016), realizaremos alguns diálogos epistemológicos para investigar o processo de constituição simbólica e imaginária dos discursos intolerantes no Brasil atual, averiguando a composição da sua racionalidade e emocionalidade, examinando suas estruturas argumentativas e analisando os regimes estéticos instituídos em suas práticas de linguagem. Discorreremos sobre cada um desses pontos em seguida.

\section{A intolerância no Brasil: aspectos históricos e epistemológicos}

Löwy (2015) aponta para o fato de que se no Brasil não há nenhum partido político formado em torno de pautas exclusivamente raciais, na Europa, não há a demanda pela instauração de uma Ditadura Civil-Militar. A despeito disso, os grupos extremistas de ambos os territórios assemelham-se pelo fato de projetarem na violência policial a solução para conflitos sociais e no conservadorismo cristão, a fonte transcendente de regulação das normas morais. Avritzer (2016) discorre sobre o esgotamento do modelo de presidencialismo de coalizão e a fragmentação do sistema partidário para explicar a crise de representatividade e a recente instabilidade institucional na Nova República brasileira, surgida com a Constituição de 1988. Serrano (2016) demonstra como a exceção, no sentido de suspensão dos direitos individuais por parte do Estado, tem se tornado regra nos sistemas jurídicos latino-americanos, ensejando um processo desconstituinte.

No aspecto simbólico, Ab'Saber (2015) avalia, dentre outros fatores, a formulação de um discurso de ódio no país que busca desautorizar qualquer manifestação no campo enunciativo associado à esquerda política. Bosco (2017) examina a relação entre a fragmentação das lutas identitárias e o seu funcionamento nas redes sociais, sendo estas últimas consideradas o novo espaço público brasileiro e instrumento que tem possibilitado os "linchamentos virtuais". Arantes (2015) avalia a "Nova Direita" como grupo político que rompe com os esquemas tradicionais da política brasileira no desejo 
de manutenção do status quo; Ribeiro (2015) pondera que tal grupo se ancora em uma agenda moral de costumes e no ódio aos direitos humanos mais do que em um projeto político; por fim, Chauí (2016) assevera que o mesmo surge da aproximação dos discursos neoliberal $^{2}$ e da Teologia da Prosperidade ${ }^{3}$, do retorno das pautas da Tradição, Família e Propriedade (TFP) à cena pública e da cultura da violência como prática do Estado brasileiro e das nossas relações sociais em todos os níveis.

Em específico, ao comentar os projetos "Escola sem Partido" e a reação à “Exposição Queermuseu”, Pinheiro-Machado (2017) assevera que a Nova Direita não é anti-intelectual, mas anti-elite intelectual. Também antidemocrática, persegue o conhecimento crítico e a justiça histórica em todas as suas acepções no intuito de formar novos regimes de verdade, legitimar a retórica autoritária e transformar os limites do que se pode dizer. Desse modo, a Nova Direita alegaria que não apenas o projeto civilizacional haveria ruído, mas que tal projeto é o responsável pela própria desigualdade, buscando se colocar como alinhada à proteção dos interesses do "povo" ao sustentar que o conhecimento humanista seria uma mera expressão do establishment político, das elites intelectuais e do poder.

Em aspectos quantitativos, o Fórum Brasileiro de Segurança Pública de 2015 chegou à conclusão de que $50 \%$ da população das grandes cidades brasileiras concorda com a expressão "Bandido bom é bandido morto" (FBSP, 2015); o dossiê Intolerâncias

\footnotetext{
${ }^{2}$ Segundo Carcanholo (2002, p. 77. Os negritos são nossos): “Atualmente a propaganda oficial e os grandes meios de comunicação (escritos, televisivos etc.) fazem-nos acreditar que a política neoliberal e o rápido e aparente inexorável processo de globalização da economia, além de inevitáveis, respondem à razão e às leis naturais". No dizer do pesquisador, tal discurso se pauta na "Síndrome da Imunidade Auto-Atribuída", apresentando a si mesmo, a um só tempo, como solução para os próprios problemas que gera enquanto sistema econômico e como meio para superar internamente suas próprias deficiências. Garantiria, com isso, um aspecto metafísico, pois causaria a si mesmo e seria desprovido de contingência.

${ }^{3}$ Chauí (2016, p. 2. Os negritos são nossos) destaca que: “[u]ma das características do neoliberalismo é a maneira como ele concebe o indivíduo, que não é entendido nem como parte de uma classe social, nem como ser em formação que vai se relacionar com o restante da sociedade. O indivíduo não é pensado nem como átomo nem como classe, mas como um investimento. [...] As igrejas evangélicas se apropriam desse ideário e o desenvolvem por meio de uma teologia - a teologia da prosperidade, que considera cada indivíduo justamente como um investimento ou uma empresa". Por questões de espaço, não desenvolveremos essa questão em profundidade no presente texto, interessando-nos apenas demonstrar como a aproximação desse discurso econômico com o discurso evangélico neopentecostal na atualidade permite uma certa deificação do mercado (inatingível e imutável) e uma reificação da religião (interessada nas conquistas materiais), associando o progresso material ao espiritual. Neoliberalismo e neopentecostalismo almejariam, portanto, conter a totalidade do sentido, na interface entre o sublime do divino (Deus) e o sublime da natureza (Razão). Safatle (2012) faz, ainda, uma interessante análise da relação entre o modelo econômico neoliberal, o qual defende amplas liberdades à concepção de indivíduo, e algumas correntes evangélicas, as quais defenderiam um amplo controle do corpo e dos impulsos individuais. Para Safatle (2012), o modelo econômico neoliberal estaria funcionando como uma espécie de compensação psíquica para esses grupos religiosos, de modo que a repressão nos aspectos espirituais da vida seria ressarcida pelo usufruto dos bens materiais no âmbito das relações sociais.
} 
Visíveis e Invisíveis no Mundo Virtual, de 2016, estima que, das 542 mil 781 mensagens analisadas nas redes sociais para monitorar manifestações de intolerância, 72,8\% dessas demonstraram intolerância visível, isto é, quando há uma discriminação direta a uma pessoa ou a um grupo. Em específico, a média relativa ao racismo atingiu 97,6\% das ocorrências, à política, 97,4\%, à classe social, 94,8\%, à homofobia, 93,9\%, à religião, 89\%, à misoginia, 88\%, e à xenofobia, 84,8\% (CQM, 2017); o levantamento do Instituto Paraná aponta que 43,1\% da população brasileira é favorável à realização de uma intervenção militar provisória no Brasil (INSTITUTOPARANÁ, 2017).

Por último, a pesquisa Medo da Violência e Autoritarismo no Brasil (FBSP, 2017) concluiu que, numa escala de zero a dez, a sociedade brasileira atingiu a marca de 8,1 na propensão a endossar posições autoritárias, com alto grau de aceitação das proposições: a ciência tem o seu lugar, mas há muitas coisas importantes que a mente humana jamais poderá compreender; os homens podem ser divididos em duas classes definidas: os fracos e os fortes; um indivíduo de más maneiras, maus costumes e má educação dificilmente pode fazer amizade com pessoas decentes; todos devemos ter fé absoluta em um poder sobrenatural, cujas decisões devemos acatar; a pobreza é consequência da falta de vontade de trabalhar.

Tais dados nos permitem desconstruir os ethé de simpatia, solidariedade e amistosidade comumente associados à ideia de "povo brasileiro". Consoante Castells $(2015$, p. 3), “[a] sociedade brasileira não é simpática, é uma sociedade que se mata. Esse é o Brasil que vemos hoje na internet. Essa agressividade sempre existiu". Para Nunes (2016, p. 3), "[a] Internet chegou para provar que somos um dos países mais racistas do mundo" e que "[n]ão há como separar o racismo cometido nas redes digitais do sistema de opressão racial que existe no Brasil fora do mundo virtual” (NUNES, 2016, p. 2).

Oz (2016) aponta que um fanático enxerga o mundo através de homogeneidades, maniqueísmos e obsessões de controle normativo do outro, carecendo, com isso, de curiosidade, empatia, ceticismo e argumentação. Barros (2007) destaca que a identidade intolerante se pauta - via maniqueísmo, moralismo, racismo e ideal de pureza - na sanção ao outro, nas paixões do medo e do ódio e no percurso temático da diferença. Para a autora, a intolerância se constitui no/pelo cruzamento de diferentes formas de intolerância, tais como a racista, a linguística, a religiosa, a social, a política e a socioeconômica, organizando-se em torno de uma forma de intolerância de base.

Eco (1995), por sua vez, atribui dez características ao que denomina Fascismo Universal, de modo que os grupos extremistas em qualquer sociedade possuiriam pelo 
menos um dos seguintes atributos: culto da tradição; rejeição ao modernismo; culto da ação pela ação; negação da crítica analítica; medo da diferença; apelo à classe média frustrada; obsessão por uma trama conspiratória; sobrevalorização, a um só tempo, da força e da fraqueza do inimigo; sensação permanente de estado de guerra; elitismo popular; culto à figura do herói; machismo; populismo seletivo; novilíngua. Por fim, Paxton (2007 apud Silva et al., 2014, p. 415) associa aos grupos fascistas as seguintes sensações: senso de crise catastrófica; primazia e vitimização do grupo considerado superior que legitima qualquer ação de extermínio do inimigo; defesa de chefes naturais sempre do sexo masculino; defesa da superioridade dos instintos do líder; direito do grupo considerado superior de dominar os demais, sem restrições de lei humana ou divina.

Sendo o Fascismo e o Nazismo modelos políticos e econômicos de Estado surgidos em um dado período histórico, é importante não atribuir a todo grupo extremista a pecha de fascista ou de nazista, sob pena de esvaziarmos a capacidade explicativa de tais conceitos. Já na década de 1940, Orwell (2017, pp. 87-8) percebe que os abusos do termo "fascismo" apontava para a sua redução semântica a um "palavrão", sendo possível ler impressos acusando de fascista grupos tão variados quanto "conservadores", "nazistas", "socialistas", “comunistas", "trotskistas", "católicos”, “os que resistem à [II] guerra", "os que apoiam a [II] guerra" e os "nacionalistas".

Interessante notar que, para o continente europeu, Löwy (2015, pp. 654-55) faz distinções entre partidos de caráter diretamente fascista ou neonazista, associados historicamente a esse campo ideológico; partidos semifascistas, com fortes características fascistas, mas sem se enquadrarem neste modelo político clássico; partidos de extremadireita, sem origens fascistas, mas com os ideais racistas, xenófobos e as retóricas antiimigrante e islamofóbica desse movimento político totalitário. Corroborando o estudioso, faremos uma breve discussão sobre os principais casos brasileiros ao longo dos séculos XX e XXI.

No Brasil, em 1932, com o Manifesto de Outubro, Plínio Salgado fundou aquilo que considerava ser um "movimento cívico-cultural": a Ação Integralista Brasileira (AIB). De acordo com Silva et al. (2014), tal agremiação teve influência direta do fascismo europeu e caracterizava-se pelo lema "Deus, Pátria e Família", pelo símbolo sigma $(\Sigma)$, em menção à ideia matemática de somatória, pelo uso de camisas verdes como uniforme e pelos discursos autoritários, nacionalistas, anticomunistas e antiliberais. Estima-se que, ao longo da década de 1930, a AIB teve entre 500 mil e 800 mil militantes, sendo considerada a maior organização fascista fora da Europa. Após o Congresso 
Integralista de Blumenau-SC, em 1935, funda-se o Partido da Ação Integralista, o qual fora fechado em 1938 após alguns de seus membros terem encampado uma tentativa de destituição do então presidente Getúlio Vargas.

A investigação de Dietrich (2011), por seu turno, lembra-nos de que o Brasil foi o país com o maior número de adeptos ao Partido Nazista fora da Alemanha, possuindo não apenas um partido dedicado a esse movimento político, mas também uma Juventude Hitlerista, os quais atuaram oficialmente de 1928 a 1938. A agremiação brasileira fazia parte de uma rede de filiais de partidos nazistas distribuídos por 83 países que recebia ordens e diretrizes diretamente do Partido Nazista Alemão. O Partido Nazista Brasileiro possuía 2900 integrantes em 17 estados brasileiros de todas as regiões do país. Segundo a pesquisadora, "o maior grupo foi o de São Paulo, com 785 membros, seguido por Santa Catarina, com 528, e Rio de Janeiro, com 447” (DIETRICH, 2011, p. 1).

Mais recentemente, Silva et al. (2014) avaliam que os principais grupos da extrema-direita nacionais são: a Sociedade Brasileira de Defesa da Tradição, Família e Propriedade, fundada em 1960 por Plínio Corrêa de Oliveira com o lema "Tradição, Família e Propriedade" (TFP), a qual se considera anti-igualitária, antiliberal, combatente do socialismo, do comunismo e defensora da tradição cristã como fundamento da coesão social, da família como alicerce da hierarquia social e da propriedade como direito natural vinculado à essência humana; os vários grupos nacionalistas e/ou neonazistas surgidos a partir da década de 1980, sobretudo em São Paulo, tais como: os Carecas do Subúrbio, grupo nacionalista com o lema "União, Força e Seriedade" e não identificado com o nazismo, os quais, com o tempo, se aproximaram dos Skinheads ingleses e passaram a cultuar o físico, a prática da defesa pessoal e o combate ao uso de drogas; e os Carecas do $A B C$, os quais romperam com o grupo anterior e retomaram o lema integralista "Deus, Pátria e Família”, passando a se associar à segregação étnico-racial e à simbologia nazista. Influenciadas por esse grupo, surgiram inúmeras outras associações neonazistas, sobretudo no Sul brasileiro, organizadas como "irmandades" e possuindo a linha de pensamento ultrarracista White Power (Força Branca) (SILVA et al, 2014).

Citando a pesquisa de Dias (2007), Silva et al. (2014) asseveram que, no início dos anos 1990, houve um crescimento significativo de grupos extremistas e/ou neonazistas no Brasil. De 2002 a 2009, por exemplo, as páginas de ambientes virtuais com conteúdos considerados neonazistas subiram de 7 mil e 600 para 20 mil 502, chegando à cifra de $170 \%$ de aumento. Nesse mesmo recorte cronológico, foi identificado o crescimento em aproximadamente $42.585 \%$ de fóruns virtuais destinados a esses temas. 
Além disso, das 250 redes sociais investigadas por Dias (2007), 91\% delas apresentaram comunidades de teor neonazista, antissemita e negacionista. De 2005 a 2013, o número de blogs com essas temáticas cresceu na marca de 550\% (SILVA et al., 2014). Consoante as autoras, "aproximadamente 150 mil brasileiros visitam mensalmente mais de cem páginas com conteúdos nazistas ou realizam mais de cem downloads" (SILVA et al., 2014, p. 431), dos quais por volta de 15 mil são considerados líderes grupais.

A expansão do pentecostalismo e do neopentecostalismo no Brasil pode estar associada à difusão de ideários mais conservadores. De acordo com Betto (2016, p. 1), entre 2000 e 2010, o número de protestantes e evangélicos no Brasil cresceu aproximadamente $61,45 \%$, chegando à casa de 42,3 milhões de indivíduos. A cada ano, acrescenta o autor, são abertos por volta de 14 mil novos templos evangélicos no país. Para o teólogo, desde o século XIX, quando os primeiros evangélicos aportaram no Brasil, de forma geral, tais grupos vêm se associando a posturas mais conservadoras, tanto no aspecto teológico quanto no político, tendo como destaques o alinhamento maciço desses grupos à Ditadura Civil-Militar e o recente combate aos direitos humanos e às causas de gênero. "A maioria dos neopentecostais se encontra nas periferias das cidades, e 63,7\% recebem por mês no máximo um salário mínimo", surgindo "[d]aí o interesse pela Teologia da Prosperidade, que propõe uma ética que transforma em valor religioso a ascensão social dentro da mobilidade urbana”, conclui Betto (2016, p. 1).

Por fim, Villazón (2015, p. 164) assevera que a América Latina vivenciou um salto expressivo na versão evangélica pentecostal nas últimas décadas, fortalecendo-se na agenda política e no debate público das normas sociais via criação de partidos evangélicos ou associações "pró-vida" e "pró-família". Para o autor, em detrimento da postura progressista desses grupos no início do século $\mathrm{XX}$, quando apoiavam a separação entre Igreja e Estado, hoje, com frequência significativa, os mesmos têm se alinhado aos grupos conservadores católicos na luta contra o que intitulam de "agenda gay" e de "ideologia de gênero".

\section{A extrema-direita como categoria de análise: proposições teórico-metodológicas}

Seguindo as discussões acima, podemos perceber que o caldo heterogêneo no qual ocorre um fortalecimento das posições conservadoras na atual sociedade brasileira torna impossível unificar na teoria o que é múltiplo nas práticas sociais. Pode-se notar que, apesar das convergências de práticas entre os distintos grupos com características 
intolerantes, há igualmente dissonâncias e contradições internas ao macrocampo do que podemos chamar hoje de "extrema-direita brasileira".

Pêcheux (2009) define o discurso como um regime de saber constituído historicamente em relação às condições materiais de existência dos grupos sociais. Com a instauração de uma discursividade, emergem um determinado campo semântico; regras de enunciação dotadas de recursividade, singularidade e raridade; o controle das vozes que podem dizer nesse espaço enunciativo; e os limites do que pode ser considerado verdadeiro de acordo com sua simbolização do mundo. Língua, história e pensamento se atravessam sem se reduzirem, deslocando o sujeito do a priori da intencionalidade e da homogeneidade psíquica para o a posteriori de uma forma da linguagem, com suas contingências e falhas constitutivas. Com isso, seus dizeres passam a ser atualizações dos já-ditos, articulações “internas” do saber que precede à sua própria subjetividade 4 . Como, então, falar de um discurso da extrema-direita brasileira na atualidade? Como proposta teórica, atrelamo-nos a quatro instrumentais epistemológicos.

Primeiro, à leitura de Hall (2003) do conceito de ideologia a partir do duplo movimento de contradição e sobredeterminação nas cadeias enunciativas, de modo que os fluxos contingentes da história seriam produzidos pela articulação entre prática e estrutura, possibilitando a emergência de formações semânticas em dominância fundamento da ideologia - constituídas como "unidade na diferença" e "diferença no mesmo". Com isso, haveria a emergência do que o sociólogo denomina "estruturas em dominância" (HALL, 2003, p. 177), as quais se caracterizariam por serem nãodeterminantes e não-necessárias (HALL, 2003, p. 185). Em certo sentido, Hall (2003) atualiza, via filosofia da linguagem althusseriana, o conceito gramsciano de hegemonia.

Segundo, à definição de Eco (1995) do fascismo como uma espécie de "jogo de linguagem", isto é, organizado por "semelhanças de família" entre as proposições, no sentido de Wittgenstein (1999). Eco (1995, p. 5. Tradução livre) afirma: “[a] noção de fascismo não é diferente da noção de Wittgenstein de um jogo. Os jogos são atividades

\footnotetext{
${ }^{4}$ De acordo com Pêcheux (2009, p. 151. Itálicos do autor): “'O pré-construído’ corresponde ao ‘sempre-jáaí' da interpelação ideológica que fornece-impõe a 'realidade' e 'seu sentido' sob a forma da universalidade (o mundo das coisas), ao passo que a 'articulação' constitui o sujeito em relação com o sentido, de modo que ela representa, no interdiscurso, aquilo que determina a dominação da forma-sujeito". E complementa a seguir: 'o que chamamos anteriormente 'articulação' (ou 'processo de sustentação') está em relação direta com o que acabamos de caracterizar sob o nome de discurso transverso, uma vez que se pode dizer que a articulação (o efeito de incidência 'explicativa' que a ele corresponde) provém da linearização (ou sintagmatização) do discurso-transverso no eixo que designaremos pela expressão intradiscurso, isto é, o funcionamento do discurso com relação a si mesmo (PÊCHEUX, 2009, p. 151. Itálicos do autor).
} 
diferentes que exibem apenas uma 'semelhança de família' [...]". ${ }^{5}$ Nessa passagem, o estudioso remete à seguinte reflexão de Wittgenstein $(1999, \S 66)$ : “O que é comum a todos eles [jogos]? [...] [S]e você os contempla, não verá na verdade algo que fosse comum a todos, mas verá semelhanças, parentescos, e até toda uma série deles".

Terceiro, à distinção realizada por Arendt (2012, p. 102) entre ralé e povo, qual seja: "[e]nquanto o povo, em todas as grandes revoluções, luta por um sistema realmente representativo, a ralé brada sempre pelo 'homem forte', pelo 'grande líder'”. Em seguida, a filósofa acrescenta: "A ralé é fundamentalmente um grupo no qual são representados resíduos de todas as classes. É isso que torna tão fácil confundir a ralé com o povo, o qual também compreende todas as camadas sociais”. Arendt (2012, p. 103) destaca que esses grupos se caracterizam pela procura daquilo que seriam as "verdadeiras forças da vida política", as quais trabalhariam atrás das cortinas, como sociedades secretas, longe dos olhos de todos. Em sua análise, afirma que, além dos judeus, maçons e jesuítas eram enquadrados nessa categoria pela ralé. Compreendendo essa dinâmica social, as elites conjunturalmente se associariam a esses grupos no intuito de potencializarem suas forças no jogo político.

Quarto, à tentativa de Cruz (2015) de superar uma definição ontológica da Direita ao colocá-la como uma categoria residual em relação à de Esquerda, sendo que esta última, independentemente das diferenças de linguagem, de forma e de características dos seus seguidores, considera injustificável a existência de desigualdades, almejando reduzir ou abolir qualquer proposição que considere a inviolabilidade, a naturalidade e a aceitabilidade de distinções essencialistas entre pessoas e grupos. Logo, a Direita seria indicada por "[...] atores individuais ou coletivos, correntes de pensamento, padrões de comportamento e atitudes que se contrapõem, nos mais diferentes contextos, a projetos dessa ordem" (CRUZ, 2015, p. 21).

Desse modo, não há nenhuma essência lógica que unifique o discurso político da extrema-direita brasileira na atualidade, sendo que, no máximo, encontraremos semelhanças de família entre os enunciados e práticas sociais dos distintos grupos que a compõem, os quais se assemelhariam pela violenta rejeição à alteridade e pela leitura dogmática das acepções de "Deus cristão", "família", "propriedade”, "nação/pátria", "hierarquia" e "ordem social". Para nós, a extrema-direita brasileira seria tanto uma "unidade na diferença" como uma "diferença no mesmo", pautada nas seguintes

\footnotetext{
${ }^{5}$ Passagem em inglês: "The notion of fascism is not unlike Wittgenstein's notion of a game. [...] Games are different activities that display only some "family resemblance,"” (ECO, 1995, p. 5).
} 
proposições: (a) o indivíduo e o grupo como fins em si mesmo; (b) a propriedade privada como direito sagrado; (c) a riqueza como índice de liberdade e de progresso individual e social; (d) a família cristã como fiadora dos valores e da moral; (e) a disposição corporativa/hierárquica como princípio de organização social da nação/povo; (f) a (re)aproximação entre Estado e Religião como garantia de hegemonia política dos grupos dominantes; e (g) a violência como condição estruturante da disciplina, da ordem e do progresso.

Acerca dos discursos de ódio, Morais (2016) sustenta que eles se estruturam metaforicamente pela negação do outro e argumentativamente - através da emergência de um "eu/nós/visão de mundo" como essências antagônicas a um "outro/terceiro/visão de mundo" -, pela construção lógica "se X é Q, logo, Y é não-Q”, em que X = não-Y. Seguindo tal fórmula, conclui-se que "se o cidadão de bem é heterossexual, (neo)liberal, militarista, patriótico e cristão, logo, o não-cidadão de bem é não-heterossexual, não(neo)liberal, não-militarista, não-patriótico, não-cristão". O conceito de cidadão de bem (metáfora ontológica) adquire positividade (metáfora de orientação) pela sua associação às características dos grupos dominantes no país, organizando a metáfora O OUTRO É INIMIGO (metáfora estrutural).

Morais (2017) afirma que o discurso político da extrema-direita brasileira na atualidade se constitui interdiscursivamente pela associação entre o discurso político, fundamento da legitimidade institucional dos dizeres, o discurso econômico neoliberal, alicerce das noções de indivíduo, liberdade, propriedade privada e empreendedorismo, o discurso conservador cristão e o discurso securitário-autoritário ${ }^{6}$ (alicerce do discurso nacionalista militar), os quais, no plano do sagrado e do profano, respectivamente, ancoram as acepções de tradição, povo, nação, ordem, disciplina, hierarquia e autoridade.

Ademais, Morais (2017, pp. 4-5) avalia as seguintes estratégias discursivas nesses grupos: (i) inversão estratégica da relação entre maioria e minoria simbólicas: posicionase como "excluído", "ameaçado", "perseguido" e "acuado", alterando, estrategicamente, a posição de "acusado/agressor/opressor" para a de "acusador/vítima/oprimido"; (ii) uso

\footnotetext{
${ }^{6}$ Conceito retirado de Faganello (2015). De acordo com esse autor, esse é o discurso que sustenta a institucionalidade da chamada "Bancada da Bala", sendo esta "a representante política de um conjunto de ideias e atitudes, que se fundamentam na percepção de que o contexto social está marcado por uma crescente e constante insegurança e desordem pública radical” (FAGANELLO, 2015, p. 151. Os negritos são nossos). Nesse sentido, "[c] oncebe-se uma apreciação da autoridade policial como uma força portadora de uma autonomia radical, a exaltação das virtudes guerreiras e do heroísmo da figura policial se conjugam com um discurso que entende a violência como ferramenta purificadora, legitimadora e resolutiva dos problemas sociais" (FAGANELLO, 2015, p. 151. Os negritos são nossos).
} 
de conceitos metafísicos como fonte do sentido: utiliza-se de conceitos com teor transcendental como forma de fundamentar a verdade última do discurso, tais como "família", "moral", "nação" e "Deus"; (iii) persuasão pelas emoções do "medo" e do "ódio": fomenta-se as sensações de insegurança e de injustiça com o fito de potencializar uma adesão e coesão primordialmente emocionais ao grupo a que pertence e a perseguição ao grupo opositor; (iv) (re)construção da encenação dos dizeres através da memória discursiva da Ditadura Militar brasileira: "atualiza-se" positivamente a memória histórica da Ditadura Militar ao definir quem é o "eu/nós" e o "outro/inimigo"; (v) homogeneização e desqualificação do "outro": constrói-se o "outro" como grupo essencializado, sem características distintivas e/ou positivas que possam humanizá-lo; (vi) violência como forma de ação legítima: associa-se a violência às necessidades de "correção", "punição", "purificação" e "resolução de conflitos sociais"; (vii) uso de termos militares para a construção da imagem de si: busca-se opor a força moral e física do enunciador à de seus opositores.

Considerando que cada discurso pressupõe uma forma de organizar sua percepção do mundo, qual seria a relação entre estética, arte e política? E mais, por que algo no campo da arte afetaria algo no âmbito do político?

\section{Estética, arte e política: interfaces conceituais}

Para Rancière (2009), a estética seria uma espécie de partilha do sensível, um modo pelo qual determinadas experiências coletivas constituem e são constituídas, a um só tempo, pela fundação de um comum e pelo recorte exclusivo das suas partes, definindo, por consequência, a partilha dos espaços, dos tempos e dos tipos de atividades que cada um exerce nessa partilha. A estética, portanto, seria uma forma organizar o mundo simbolizado, de modo que tanto a arte quanto a política, embora distintas entre si, perspectivariam as experiências sociais, selecionariam sentidos e estabeleceriam relações entre os sujeitos em um dado espaço-tempo.

De acordo com Rancière (2010), se tanto a arte quanto a política possuem uma estética, isso decorre do fato de que ambas são práticas vinculadas à elaboração, material e simbólica, de uma ficção do comum e do diferente. Ademais, esses regimes de sensibilidade se atravessariam na reconfiguração dos espaços, tempos e identidades um do outro, tornando possível tanto uma "estética da política" quanto uma "política da estética". "Política e arte, tanto quanto os saberes, constroem 'ficções', isto é, rearranjos 
materiais dos signos e das imagens, das relações entre o que se vê e o que se diz, entre o que se faz e o que se pode fazer", sustenta Rancière (2009, p. 59. Os negritos são nossos).

Apesar disso, o espaço de apresentação da arte institui que as "coisas da arte" sejam identificadas enquanto tais, adquirindo certa autonomia em relação à política. Assim, a arte não se reduziria ao político nem "pelas mensagens e pelos sentimentos que transmite sobre a ordem do mundo" nem "pelo seu modo de representar as estruturas da sociedade, os conflitos ou as identidades dos grupos sociais" (RANCIÈRE, 2010, p. 20).

No que concerne à arte enquanto campo específico da experiência coletiva, cumpre-nos destacar que Rancière (2010, pp. 27-33) propõe a existência de três regimes históricos de identificação, a saber: o regime ético; o regime poético ou representativo; o regime estético. Cada um com distintas formas de ligação entre os "modos de produção das obras ou das práticas", as "formas de visibilidade dessas práticas" e os "modos de conceituação destas ou daquelas".

O primeiro desses regimes seria aquele encontrado na filosofia de Platão, no qual não faz sentido a diferenciação entre política e arte, visto que esta última não se definia ainda como um campo apartado das outras práticas sociais. Fala-se em "ético" pelo fato de as imagens remeterem ao ethos, isto é, aos modos de existência dos indivíduos e da coletividade, seus costumes e suas práticas. Nesse caso, em vez de arte, existiam artes, como distintas "maneiras de fazer". A distinção entre estas decorria apenas da oposição entre "artes verdadeiras" - tidas como saberes fundados na imitação de um modelo com fins definidos - e "simulacros de arte" - os quais se pautam na imitação de simples aparências" (RANCIÈRE, 2010, p. 30).

O segundo regime, o poético/representativo, separa-se do anterior ao considerar as imagens a partir dos conceitos de poiesis - como maneira de fazer e agir - e mímesis - como princípio pragmático que especifica, no domínio geral das maneiras de fazer, as artes - aquelas responsáveis por produzirem imitações. Constitui-se, assim, um domínio consistente de imitações que cria uma linha entre o que pode ou não ser incluído nesse regime e um modo de apreciação que define as imitações como boas ou ruins, adequadas ou inadequadas. Institui-se, por conseguinte, a "separação entre representável e irrepresentável”, a "distinção de gêneros em função do que é representado" e a elaboração de "princípios de adaptação das formas de expressão aos gêneros", "aos temas apresentados", à “distribuição de semelhanças segundo princípios de verossimilhança", "à conveniência ou correspondência" e aos "critérios de distinção de comparação entre as artes" (RANCIÈRE, 2010, p. 31). 
A partir de então, pode-se falar de uma autonomia dessas práticas em relação à ordem geral das maneiras de fazer e das ocupações. Isso não impede, entretanto, que esse saber artístico emerja por uma espécie de analogia global em relação à hierarquia global das demais ocupações políticas e sociais, quais sejam: o "primado representativo da ação sobre os caracteres, ou da narração sobre a descrição"; a "hierarquia dos gêneros segundo a dignidade dos seus temas" e, por fim, "o próprio primado da arte da palavra, da palavra em ato" (RANCIÈRE, 2010, p. 32). Seriam essas as três formas de relação entre a estética da política e a política da estética nessa organização dos saberes.

Por fim, temos o regime estético, o qual se contrapõe ao regime poético a partir do século XVIII, quando as interpretações de Kant e Schiller atribuem à arte o tratamento do belo e do sublime. "Ele afirma a absoluta singularidade da arte e destrói ao mesmo tempo todo critério pragmático dessa singularidade. Funda, a uma só vez, a autonomia da arte e a identidade de suas formas com as formas pelas quais a vida se forma a si mesma", salienta Rancière (2010, p. 34). A partir de então, a arte deixa de remeter a uma maneira de fazer específica frente as demais para se associar à fundação de um modo de ser sensível específico aos produtos da arte. Ademais, rompe-se com qualquer regra particular, bem como com toda hierarquia inerente aos temas, gêneros e artes.

A modernidade, de acordo com Rancière (2010, pp. 38-9), é composta, de um lado, pela revolução "anti-mimética", a qual institui a autonomia da arte, a "conquista da forma pura" e a "pura potência da arte", de outro, pelo modernitarismo, fruto da educação estética do homem de Schiller, na qual, resguardando a ideia de arte como forma e autoformação da vida, associa-se tal sensibilidade a uma espécie de destino próprio da modernidade, subsistindo a possibilidade de um estado neutro do sensível, o qual decorreria da dupla anulação entre atividade do pensamento e receptividade sensível.

O que se chama de "crise da arte" coincide com a ruptura, no século XX, entre o(s) modernismo(s) e o pós-modernismo. Se a modernidade se pautava em um modelo ontológico-estético, teleológico - corte temporal efetivo como fim real de um tempo histórico - e na fundação de um "próprio da arte", a pós-modernidade, de acordo com Rancière (2009, p. 41), trouxe, com o Outro, as potências heterogêneas do sensível, propondo "as passagens e misturas entre as artes", o "retorno da linha curva e do ornamento", a "ruína do modelo pictural/bidimensional/abstrato através dos retornos da figuração e da significação", a "lenta invasão do espaço da exposição das pinturas por formas tridimensionais e narrativas", as "combinações da palavras e da pintura" e, por fim, as "misturas de gêneros, épocas e sistemas musicais". 
O pós-modernismo, de um lado, exaltaria os simulacros, a mestiçagem e as hibridações, almejando o irrepresentável, o intratável e o irrecobrável ao considerar o belo e o sublime como cenas de fundação de uma distância entre a ideia e toda representação sensível, e não mais como ponto de partida ou de busca; de outro, arruinaria o edifício teórico do modernismo, com a concepção de que a arte deveria cumprir uma missão, devedora de uma certa noção de vanguarda focada na "noção topográfica e militar da força que marcha à frente, que detém a inteligência do movimento, concentra suas forças, determina o sentido da evolução histórica e escolhe as orientações políticas subjetivas" (RANCIÈRE, 2009, p. 43. Grifos nossos).

Interessa-nos, especialmente, avaliar como arte e política e seus respectivos regimes específicos de visibilidade podem se atravessar, dado que as características trazidas pelo pós-modernismo, com a destruição das fronteiras hierárquicas entre os gêneros, bem como com a distanciação da ideia de arte daquela de belo e sublime parecem reverberar também no campo do político. Trataremos desses aspectos na seção seguinte.

\section{1. A Mostra Queermuseu: apontamentos para uma estética da intolerância}

Inaugurada em 14 de agosto de 2017, no Santander Cultural, em Porto Alegre, a exposição Queermuseu: cartografias da diferença na Arte Brasileira, foi encerrada menos de um mês após a sua abertura ao público. Sob a curadoria de Gaudêncio Fidélis, a Mostra era composta por um total de 270 obras de 85 artistas, as quais foram produzidas entre o início do século XX e a atualidade. Em 06 de setembro de 2017, Júnior (2017) publica um artigo de opinião intitulado "Santander Cultural promove pedofilia, pornografia e arte profana em Porto Alegre", o qual foi considerado um dos principais vetores de reação à Exposição. Após manifestações de alguns grupos nas redes sociais, no próprio espaço cultural e a polêmica gerada na mídia nacional, em 10 de setembro de 2017, o Santander Cultural decidiu encerrar a Exibição. Em seu texto, Júnior (2017. Os itálicos são do autor. Os negritos são nossos) afirma:

O Santander Cultural está sediando a exposição Queermuseu, na cidade de Porto Alegre. São cerca de 270 obras que promovem a pedofilia, a pornografia e os mais variados ataques à moral e aos bons costumes que se possa imaginar. [...] Há, é claro, no mínimo uma confusão entre processo criativo e necessidade de expor intimidades. [...] Gaudêncio Fidelis, o curador da exposição, pode até ter doutorado em história da arte, mas certamente arte não é a sua especialidade, apenas confusão. [...] Primeiramente, ele fala na diferença como alteridade. Isso não passa de um curto-circuito cerebral dos ditos especialistas em arte contemporânea que 
já há tempos se distanciaram do verdadeiro objetivo da arte: a consagração do belo. Hoje o artista precisa causar impacto, e só. [...] Para sujeitos assim, a tradição não tem qualquer papel numa sociedade a não ser oprimir desejos insaciáveis e estabelecer parâmetros normativos para enquadrar as pessoas em determinadas categorias. Observe como um depravado começa a perverter o vocabulário da língua portuguesa. Ele diz que o termo queer, que dá nome à exposição, apresenta um "significante não normativo". Traduzindo: trata-se de um termo fora da norma previamente estabelecida. Para Fidelis, a criação de barreiras normativas criou uma barreira conservadora e uma política de diferenças. Os únicos movimentos que impõem tais diferenças são os movimentos das minorias. Eles não querem igualdade coisíssima nenhuma, mas a criação de amplos poderes para formação de classes de intocáveis. A exposição quer desafiar os modelos curatoriais tradicionais, especialmente aqueles de perspectiva heteronormativa [...] Para os novos parâmetros da arte, a beleza pouco importa se o artista for capaz de causar espanto, de transgredir normas e inserir os seus trabalhos numa proposta de gênero. Poucos sabem que a arte é uma forma de transcender o barbarismo e as limitações do imaginário humano, na busca incansável pelos altos picos de realização do homem: é um ato de defesa da civilização.

Dois dias após o fechamento da Exposição, em 12 de setembro de 2017, Santos

(2017) também posiciona-se sobre os aspectos artísticos e políticos da mesma no texto intitulado Exposição fechada mostra que brasileiro não é mais cordeirinho, reforçando, grosso modo, os argumentos apresentados por Júnior (2017). Seguem partes do texto:

[...] A exposição em si é recheada de zoofilia, ofensas à fé cristã e imagens sexualizadas de crianças; pretende-se que escolas públicas e privadas façam visitas monitoradas, e material impresso foi feito - com dinheiro público para ilustrar essas visitas. O site Lócus foi o primeiro a denunciar. Após isso, a sociedade civil - Movimento Brasil Livre (MBL) incluso - protestou contra o absurdo. Vale lembrar: membro algum do movimento se manifestou no local ou constrangeu os presentes, prática costumeira da esquerda. Quem faz uso recorrente da violência são os mesmos que agora reclamam da nossa manifestação republicana. Após contundente pressão popular, o Santander Cultural recuou e decidiu cancelar a "exposição". Democraticamente. Reconhecendo seu erro. Dali em diante, a velha imprensa entrou em campo. [...] Manifestações de ódio, difamação e incitação à violência foram a tônica da turminha dos "ilustrados do bem". Lamentamos. O MBL preza a civilidade e o bom debate público e teme a escalada de violência e intolerância política advinda, especialmente, de setores da nossa imprensa. O que eles querem, no fim, é que uma elite política e cultural continue utilizando dinheiro público para desrespeitar e vilipendiar os valores mais profundos da sociedade brasileira, dela exigindo que entregue seu dinheiro de forma silente e resignada. Que saibam, porém, que novos tempos chegaram. Os brasileiros não são mais um cordeirinho calado, cujo destino é muito bem ilustrado por uma das obras expostas pelo Santander (SANTOS, 2017. Os negritos são nossos).

Esse debate volta a ficar em evidência menos de um mês após o fim da Mostra quando, em 07 de outubro de 2017, a Câmara dos Vereadores de Uruguaiana, no Rio Grande do Sul, propõe que o livro Queermuseu: cartografias da diferença na arte 
brasileira - componente do acervo da Biblioteca Pública da cidade - seja retirado desta instituição. Além disso, a casa parlamentar publica uma moção de repúdio ao Santander Cultural, na qual afirma:

\begin{abstract}
"O Brasil enfrenta uma 'Crise Moral' no que se refere a manifestações ditas culturais de gosto e interpretações duvidosas, que em alguns casos, afrontam religiões, colocam em risco menores de idade, quando as expõe a ambientes onde se caracterizam a pedofilia e a zoofilia e a outras situações que se não constrangem, faz com que as crianças estejam a merce de ideologias que além de distorcidamente permissivas, são potencialmente nocivas para a formação de caráter". A Moção ao Santander Cultural considera a obra de mau gosto, com conteúdos que passam pelo grotesco, pela lascívia distorcida e pela desnecessidade, além da falta de talento camuflada e eclipsada pela pretensa tentativa de "chocar a sociedade". [...] "Mesmo com muito esforço, não podemos encontrar uma mísera migalha de virtude na obra. Em casa tudo bem, mas no espaço da biblioteca não agrega e não constrói. Entendemos imoral e inadequado [...]" (CÂMARAMUNICIPAL, 2017, p. 1. Os negritos são nossos).
\end{abstract}

No processo de discussão sobre os parâmetros da "verdadeira arte", os textos passam a tecer críticas pessoais e profissionais ao curador, à academia e à classe artística, incorrendo nas seguintes estratégias argumentativas: inversão estratégica da relação entre maioria e minoria simbólicas, estabelecendo uma falsa simetria para atribuir aos grupos associados à defesa da Mostra manifestações de ódio, difamação, violência e desrespeito; uso de conceitos metafísicos como fonte do sentido; persuasão pelas emoções do "medo" e do "ódio"; homogeneização e desqualificação do "outro" (argumentos ad hominen); violência (nesse caso, verbal) como forma de ação legítima (MORAIS, 2017); uso do conceito de norma - social ou linguística - com base na concepção de pureza (BARROS, 2007); percepção das "minorias" e da "elite política e cultural" como uma espécie de sociedade secreta ou inimiga ("classe de intocáveis") (ARENDT, 2012); significação do "novo" por um "elitismo popular" e um "populismo seletivo", atribuindo a uma parcela do "povo" o locus da verdade e da potência de poder (latente ou patente), medo da diferença e obsessão por uma trama conspiratória (ECO, 1995) e senso de crise catastrófica (PAXTON, 2007).

A ressignificação do conceito político de "civilização" como objeto da arte em Júnior (2017) essencializa a diferença por uma suposta igualdade, visto que as "diferenças" seriam criações das minorias na busca pelo poder. No entendimento de que todos seriam iguais, legitima-se o esquecimento das desigualdades pela exclusão das vozes dissonantes. Semelhante ao regime poético, separa-se o representável do irrepresentável, elabora-se princípios de verossimilhança e critérios de distinção e de 
comparação entre as artes. Os símbolos e materialidades do status quo social funcionam como medidas para a arte, a qual estaria em constante decaimento pelo distanciamento das origens, pela vitória do grotesco e pela perda de sentido. Seguem as cadeias semânticas dos textos:

$$
\begin{aligned}
& \text { A) Arte } \rightarrow \text { domínio autônomo } \rightarrow \text { transcendência } \rightarrow \text { universal } \rightarrow \text { sagrado } \rightarrow \\
& \text { pureza } \rightarrow \text { belo } \rightarrow \text { moral } \rightarrow \text { virtude } \rightarrow \text { tradição } \rightarrow \text { caráter } \rightarrow \text { bom gosto } \rightarrow \text { norma } \\
& \rightarrow \text { criatividade } \rightarrow \text { verdadeiro } \rightarrow \text { pedagógica } \rightarrow \text { família } \rightarrow \text { bons costumes } \rightarrow \\
& \text { consagração do belo } \rightarrow \text { realização do homem } \rightarrow \text { heteronormatividade } \rightarrow \text { defesa } \\
& \text { da civilização; }
\end{aligned}
$$

B) Exposição Queermuseu $\rightarrow$ elite política e cultural $\rightarrow$ minorias $\rightarrow$ pedofilia $\rightarrow$ pornografia $\rightarrow$ zoofilia $\rightarrow$ depravação $\rightarrow$ perversão $\rightarrow$ imoralidade $\rightarrow$ diferença $\rightarrow$ confusão $\rightarrow$ espanto $\rightarrow$ barbarismo $\rightarrow$ grotesco $\rightarrow$ desnecessidade $\rightarrow$ poder $\rightarrow$ arte profana $\rightarrow$ mau gosto $\rightarrow$ falta de talento $\rightarrow$ ataque à moral $\rightarrow$ ofensa à fé cristã $\rightarrow$ lascívia distorcida $\rightarrow$ limitações do imaginário humano $\rightarrow$ necessidade de expor intimidades $\rightarrow$ sexualização das crianças $\rightarrow$ curto-circuito cerebral $\rightarrow$ desafio aos modelos curatoriais tradicionais $\rightarrow$ queer $\rightarrow$ proposta de gênero $\rightarrow$ transgressão de normas $\rightarrow$ significante não-normativo $\rightarrow$ novos parâmetros da arte $\rightarrow$ tentativa de chocar a sociedade.

Tomando por parâmetro a primeira cadeia conotativa, a arte parece associada a uma unicidade - a Arte -, a uma mistura de dois regimes artísticos - o poético e o estético - e a um regime moral - o cristão. O belo e o sublime estariam atrelados, a um só tempo, a uma certa ficção representativa, mímesis da ordem das coisas do mundo como é, e a uma certa ficção sacra, busca da ordem das coisas do mundo como deveria ser, subsumindo o primeiro, como experiência ordinária, à tentativa de retorno a um estado anterior a toda forma de divisão particular, isto é, ao divino. As coisas da arte deveriam, portanto, retomar a verossimilhança com o belo e sublime considerando a hierarquia dos temas de acordo com sua associação aos cânones morais religiosos, os quais representam as hierarquias no mundo. Seu aspecto pedagógico retira sua força dessa analogia, propondo um modelo espiritual que deve formar o caráter dos indivíduos e da coletividade, ou seja, do comum e de suas partes, na arte e no mundo. 
Desse modo, uma certa visão política da arte - o belo e o sublime associados ao sagrado e à civilização - parece projetar os valores para uma visão artística da política, a qual não existe em si, mas que deve ser buscada incansavelmente. Sendo a arte uma forma de representar o anterior ao mundano, ela teria em si um papel pedagógico no desenvolvimento do bom gosto, do belo e do correto. Tanto quanto a arte, a educação deveria possuir uma conotação não ideológica, como seria, em última instância, o ideal da política, decaída pelo dissenso.

Para isso, precisam abdicar dos especialistas em arte, profanados pelo ideológico e pela busca do conflito, em vez de serem fiéis às purezas espiritual e natural e ao harmônico das relações sociais, comumente associados às figuras da divindade e santidades, à infância e à experiência popular; os quais funcionariam como critérios do bom e do ruim, do adequado e do inadequado. A sexualidade, em um viés cristão, seria o símbolo da impureza, do profano, do impulso, do descontrole, das paixões, do prazer, do instável, dos baixos instintos, do animalesco em relação à civilidade, enfim, da reprodução em relação à origem. No que tange à homossexualidade, tratar-se-ia, além do carnal, da indisciplina em relação à ordem natural e/ou espiritual das coisas, da desorganização da hierarquia originária dos grupos, da ruptura da própria reprodução ritualizada da origem, incorrendo no contingente em vez do universal, no grotesco em vez do belo, na imprecisão em vez do limite e no absurdo em vez do sentido.

Nessa forma de interpretação do regime poético ("hierarquias" e "distinções de valores") pelo regime estético ("transcendências" e "culto ao belo"), define-se o que é arte pela negação de qualquer "[...] redistribuição dos lugares e das identidades, do visível e do invisível, do barulho e da palavra" (RANCIÈRE, 2010, p. 21). Nesse cruzamento de regimes de identificação do artístico, a distinção se transforma no dever ser, na arte e no mundo, sendo que a ruptura com esses critérios representaria a ausência de normas universais. Desse modo, a negação do Outro - com suas distintas formas de pensar a arte, os temas e o entendimento da ausência de distinções ontológicas entre eles - ocorre pela procura dogmática do ontológico-estético da imagem primeira: o belo e o sublime não seriam propriedades de ninguém, visto que se instituem como um estado neutro da sensibilidade frente ao que é artístico; apenas são.

A arte funcionaria nesse caso como um modelo não-ideológico para as sociedades, a partilha do sensível que não incorre na dinâmica conflituosa - do comum e das partes da política, a qual também deveria se fundar no verdadeiro e na tradição. Busca-se na arte, enquanto forma de organização das experiências coletivas, o anterior à política, o $a$ 
priori à presença do Outro, ou seja, uma experiência sensível de retorno ao uno, ao imutável, à manutenção e à restauração da cena de origem. Almeja-se superar o contraditório da estética política pelo estado neutro da política da estética. Sem consenso não há arte, sendo esta, por definição, o lugar da não-política. Tomando-a como fundamento de um regime de saber da política, as desigualdades entre os indivíduos seriam essenciais e intransponíveis, isto é, igualmente desiguais, pois remetem a uma única cena de origem, isto é, a espaços, tempos e funções de uma espiritualidade e naturalidade, devendo serem respeitadas, a fim de atingirem o belo e o sublime.

Se a arte é a expressão da civilização, a civilização é a expressão do mesmo - do igual universal - em oposição ao diferente contingente. Logo, qualquer ruptura na arte romperia com o ideal de civilização na política. A tentativa de chocar a sociedade pela arte é, por consequência, a tentativa de chocar a civilidade, suas normas e funções. Desse modo, os três textos procuram, por uma leitura artística do viés político, instituir a nãopolítica como padrão (implícito e/ou explícito), significando o harmônico pelo hegemônico, passando também este a ser sacralizado e naturalizado. Negando a política fazem a mais agressiva das políticas, em ambos os regimes estéticos, na qual as vozes das imagens e da polis reduzem o representável aos cidadãos civilizados - dotados de palavra - e o irrepresentável, aos escravos bárbaros, ou seja, àqueles dotados apenas de barulho.

Com isso, parecem constituir uma forma particular de regime de sensibilidade/experiência, no qual o comum e a distribuição das funções pressupõem exclusão, anulação e desumanização - material e simbólica - do Outro, tido como elemento exógeno que tenta constantemente colocar em causa a harmonia das coisas, na arte e na política; isso fundaria, a nosso ver, o pilar de uma estética da intolerância. Nela, o comum se pautaria pela reprodução das estruturas materiais e simbólicas dos grupos identitários hegemônicos, modelos do verdadeiro e do falso, do belo e do feio, do bem e do mal, do agradável e do desagradável e do útil e do inútil, os quais seriam parâmetros para todas as práticas de linguagem.

Nessa estética artística da política, a negação da alteridade almejaria decidir quem é o cidadão, sua voz, seu corpo, sua forma e suas normas, a partir das quais se permite criar os direitos - à imagem e à comunidade - do homem e negá-los ao não-homem, isto é, ao incivilizado. Pela busca da cena de origem metafísica e sua manutenção pela tradição, pela necessidade de manutenção da hierarquia e da ordem e, por fim, pelo desejo de ausência do conflito interno, o artístico, o religioso e o militar parecem se tornar modelos ideais do dever ser, impondo-se sobre a política como forma de normatizá-la. A 
intolerância, nesse sentido, é a negação da política ou, pelo menos, a farsa da política como consenso a priori e hegemonia inviolável dos cidadãos que detêm o poder: físico, simbólico e sistêmico.

Isso parece explicar, em parte, a reação à Mostra Queermuseu como ofensa à arte, à sociedade, aos símbolos religiosos, às normas morais e ao modelo de cidadão. $\mathrm{O}$ "público" também seria anterior ao conflito, tendo no "Estado" o gestor dos interesses do “povo". Daí a escandalização do uso do "dinheiro público" para promover as "grotescas" intenções políticas, no sentido de ideológicas, dos "especialistas em arte contemporânea", dos "ilustrados do bem", da "elite política e cultural" e dos "movimentos de minorias". A política se torna acusação de sectarismo; na arte não devem aparecer os desejos privados dos homens, psíquicos e sociais.

Resta-nos, ainda, aprofundar como esse campo semântico do papel da arte poderia se associar aos demais aspectos do discurso da extrema-direita brasileira na atualidade, constituído na interface entre o discurso neoliberal (com foco nas "relação econômicas"), o discurso securitário-autoritário e/ou militarista (com foco na "ordem pública") e o discurso conservador cristão (com foco na "moral pública"). Dito de outro modo, haveria um regime de sensibilidade transversal a essas distintas formas de organizar o sensível? Caso sim, como?

Se cruzarmos a primeira cadeia semântica - sobre a "arte" - com as contribuições de Arendt (2012), Barros (2007), Cruz (2015), Eco (1995), Oz (2016) e Paxton (2007) e com os lemas "Deus, Pátria e Família”, da AIB, "Tradição, Família e Propriedade”, da TFP, e "União, Força e Seriedade", dos Carecas do Subúrbio, veremos como o significante arte - no sentido de defesa da civilização - pode se associar aos signos Deus (sacralidade, indivisibilidade e inviolabilidade da cena de origem, da espacialidade do divino e da perfeição do pai), pátria (sacralidade, indivisibilidade e inviolabilidade da espacialidade de um povo, também sacralizado, indivisível e inviolável), propriedade (sacralidade, indivisibilidade e inviolabilidade do direito/espaço familiar), família (sacralidade, indivisibilidade e inviolabilidade da cena de origem do clã, da hierarquia, das normas e dos laços de consanguinidade de um indivíduo), tradição (sacralidade, indivisibilidade e inviolabilidade da temporalidade do grupo e da sua relação com a cena de origem), união (sacralidade, indivisibilidade e inviolabilidade da coesão e harmonia do grupo), força (sacralidade, indivisibilidade e inviolabilidade da superioridade, 


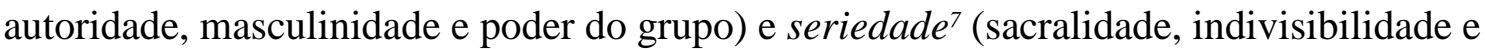
inviolabilidade das normas e ritos do grupo), os quais representariam para esses grupos, em qualquer regime estético, a ausência de conflitos e o respeito aos vínculos espirituais e/ou naturais entre os indivíduos. Ocorre, assim, uma sacralização do natural e uma naturalização do sagrado.

Em consonância com Pinheiro-Machado (2017), entendemos que tais discursos se pautam em um posicionamento anti-elite intelectual e antidemocrático. Diferentemente da autora, consideramos que há nos movimentos intolerantes uma intenção civilizacional, embora não calcada no humanismo, visto que qualquer grupo que almeje a hegemonia simbólica e imaginária em uma sociedade vê em si mesmo e nas suas ações a legitimidade e a superioridade do seu regime de saberes em detrimento daquele do seu oponente, sob pena de não legitimar-se nem para si mesmo. Crê, portanto, na transcendência das suas virtudes, associada aos verdadeiros valores morais, mesmo que isso possa levar a uma ética violenta e excludente.

Assim, sustentamos que a partilha do sensível na subjetividade intolerante se funda através de uma sensibilidade dogmática - como simbolização da experiência individual e grupal como verdade última - em relação aos seguintes aspectos: ideal de pureza: o divino, a natureza e o bem - vinculados à universalidade estética e moral da cena de origem mítica - em oposição ao profano, ao ideológico e ao mal, expressões do grotesco e da desonra dos homens; tradição como fundação do sentido de existência: longa temporalidade da norma como símbolo de autenticidade em oposição à ilegitimidade do novo; hierarquia como distinção ontológica de valores e funções: espaço essencialmente não-igualitário e disciplinado em oposição à ausência de distinções e à desordem; exclusão de objetos imprecisos: o particular, a clareza e o limite em oposição à multiplicidade, à mestiçagem/hibridação e à porosidade; maneira de fazer como remissão a uma sacralidade: ações como missões do dever ser em oposição à subversão dos procedimentos.

Associados a uma leitura fundamentalista, esses cinco pressupostos estéticos circulam na definição da partilha do sensível intolerante dos discursos político, responsável pela definição do cidadão e do não-cidadão, neoliberal, responsável pela definição do indivíduo/grupo como fim em si mesmo e da racionalidade natural das suas

\footnotetext{
${ }^{7}$ Eco (2012), por meio da narrativa literária, ajuda-nos a visualizar como a "seriedade" pode ser significada como respeito ao sagrado e ao autocontrole do corpo e como o "riso", por oposição, pode se associar ao escárnio do divino e se opor à doutrina ascética.
} 
relações de troca, militar, responsável pela definição das tradições da pátria, da hierarquia natural do corpo social e da disciplina como fundamento laico para os rituais do corpo, e o religioso, responsável pela definição das tradições sacras, da moral transcendente e da família como célula social vinculada à ancestralidade comum.

O inimigo seria corporificado na figura da constante ameaça, visível ou oculta, no temor de ruptura dos laços, no perigo de desagregação dos vínculos, no risco de profanação dos valores e na destruição dos direitos e da memória do grupo, fomentando o medo (distanciamento do outro), o ódio (repulsa ao outro e concentração das frustrações no objeto negado), a violência (anulação física, simbólica e sistêmica do outro, conforme tipologia de Drawin (2016)) e a constante vigilância (estado de guerra permanente ao outro). Nesse sentido, o inimigo seria a projeção em um objeto simbolizado como exterior ao grupo da demanda de coesão interna do grupo. Ou seja, odeia-se os inimigos externos na mesma proporção da internalidade dos medos e das frustrações do grupo ${ }^{8}$.

A centralidade dos aspectos perceptuais supracitados, bem como seu movimento sígnico transdiscursivo, permite a fundação de uma organização simbólica e material transestética. Pensar nessa associação entre uma transdiscursividade e uma transesteticidade permite à nossa abordagem explicar como a perspectiva intolerante tende a se manifestar em distintas práticas discursivas (artística, política, religiosa, securitária, linguística, econômica etc.) com padrões semelhantes, avançando nos seguintes entendimentos: de um lado, como os mesmos significantes, apesar de circularem em "distintos espaços discursivos", conseguem manter coerência semântica, lógica argumentativa e articularem uma coesão interdiscursiva e ideológica específica; de outro, como a estética e a discursividade estão necessariamente conectadas na constituição das subjetividades, fundando uma regularidade singular na maneira como o sujeito e os grupos percebem o mundo e organizam suas materialidades, causalidades e consequências. Do discurso transverso em Pêcheux (2009), estamos propondo a irrupção de uma sensibilidade transdiscursiva em dominância.

Para finalizar, embora as figuras do "eu/nós" e do "outro" emerjam nas/pelas contingências da história, a partilha do sensível nas subjetividades intolerantes parece conter um comum semântico ao longo do tempo e dos espaços: a desumanização do outro; a qual emerge, notadamente, em situações de assimetrias extremas nas relações de poder

\footnotetext{
${ }^{8}$ Sobre a organização libidinal dos indivíduos nas massas e sobre as projeções identitárias dos indivíduos na figura do líder em organizações fundadas na extrema disciplina, tais como nas religiões e nas Forças Armadas, remetemos a Freud (2011).
} 
e na erosão de um determinado status quo. Logo, é preciso haver uma reação à ameaça à hierarquia de poder para haver intolerância, sob pena de sustentarmos uma falsa simetria entre as ações dos que buscam a anulação do outro e as daqueles que buscam conquistar o status de uma voz. É, enfim, na rigidez excludente e essencializante da divisão das partes e dos lugares que se funda a experiência da subjetividade intolerante, como uma maneira de organizar as percepções, razões e emoções no/sobre o mundo, de modo que as buscas da pureza, da tradição, da hierarquia e da distinção de valores morais não trazem em si o fanatismo.

\section{Considerações finais}

Neste trabalho dedicamo-nos a investigar a relação entre estética e intolerância, arte e extremismo político no Brasil atual. Desse modo, se, na primeira metade do texto, priorizamos discussões a respeito das características da intolerância, perpassando os aspectos históricos e epistemológicos do conceito, na segunda metade, enveredamos por esse debate através da incorporação do conceito de estética, nos termos de Rancière (2009; 2010). Sugerimos, com isso, a possibilidade de tratar de uma estética da intolerância, como emergência de uma transesteticidade e de uma transdiscursividade. Em trabalhos futuros, pretendemos avaliar a relação entre essa estética e o campo visual, incorporando ao corpus parte das obras expostas na Mostra Queermuseu para um aprofundamento epistemológico da categoria.

\section{REFERÊNCIAS BIBLIOGRÁFICAS}

AB'SABER, T. Dilma Rousseff e o ódio político. São Paulo: Editora Hedra, 2015.

ARENDT, H. As origens do totalitarismo: antissemitismo, imperialismo e totalitarismo. São Paulo: Companhia das Letras, 2012.

AVRITZER, L. Impasses da democracia no Brasil. Rio de Janeiro: Editora. Civilização Brasileira, 2016.

BARROS, D. L. P. de. A identidade intolerante no discurso separatista. Filologia Linguística Portuguesa, $\mathrm{n}^{\mathrm{o}}$ 9, pp. 147-167, 2007. Disponível em: < http://www.revistas.usp.br/flp/article/view/59777>. Acesso em: 10/10/2016.

BOSCO, F. A vítima tem sempre razão? Lutas identitárias e o novo espaço público brasileiro. São Paulo: Editora Todavia, 2017.

CARCANHOLO, R. A. A globalização, o neoliberalismo e a síndrome da imunidade auto-atribuída. In: MALAGUTTI, M. L.; CARCANHOLO, R. A; CARCANHOLO, M. D. Neoliberalismo: a tragédia dos nossos tempos. São Paulo: Cortez, 2002. 
CRUZ, S. V. Elementos de reflexão sobre o tema da direita (e esquerda) a partir do Brasil no momento atual. In: CRUZ, S. V; KAYSEL, A.; CODAS, G. (orgs.). Direita, volver!: o retorno da Direita e o ciclo político brasileiro. São Paulo: Edição Fundação Perseu Abramo, 2015, pp. 13-48.

DIAS, A. Os anacronautas do teutonismo virtual: uma etnografa do neonazismo na internet. Tese de doutorado. Campinas: Unicamp, 2007. Disponível em: <http://repositorio.unicamp.br/bitstream/REPOSIP/279037/1/Dias_AdrianaAbreuMagal haes_M.pdf $>$. Acesso em: 28/01/2018.

DIETRICH. A. M. Narrativas orais da Juventude Hitlerista e Neonazista no Brasil: breve análise comparativa. Anais do XXVI Simpósio Nacional de História - ANPUH. São Paulo: julho 2011. Disponível em: http://www.snh2011.anpuh.org/resources/anais/14/1300553634_ARQUIVO_2dietricha npuh2011.pdf>. Acesso em : 26/01/2018.

DRAWIN, C. R. Clamor e silêncio da violência. In: MOREIRA, J. de O., NETO, F. K. ; ROSÁRIO, A. B. do (Orgs.) Violência(s): diálogos com a Psicanálise. Curitiba : CRV, 2016.

ECO, U. Ur-Fascism. The New York Review of Books, pp. 1-9, junho de 1995. Disponível em: 〈http://www.pegc.us/archive/Articles/eco_ur-fascism.pdf > . Acesso em: 01/08/2017.

ECO, U. O nome da rosa. Rio de Janeiro: Best Bolso, 2012.

FAGANELLO, M. A. Bancada da Bala: uma onda na maré conservadora. En S. V Cruz; A. Kaysel; G. Codas (orgs.). Direita, volver!: o retorno da Direita e o ciclo político brasileiro, pp. 145-161. São Paulo: Edição Fundação Perseu Abramo, 2015.

FREUD, S. Psicologia das massas e análise do eu. In: FREUD, S. Obras completas (19201923). V. 15. São Paulo: Companhia das Letras, 2011, pp. 10-100.

HALL, S. Significação, representação, ideologia: Althusser e os debates pósestruturalistas. In: HALL, S. Da diáspora: Identidades e mediações culturais. Organização Liv Sovik. Belo Horizonte: Editora UFMG, 2003.

LÖWY, M. Conservadorismo e extrema-direita na Europa e no Brasil. Serviço Social \& Sociedade, $\mathrm{n}^{\mathrm{o}}$ 124, pp. 652-64, 2015. Disponível em: http://www.scielo.br/pdf/sssoc/n124/0101-6628-sssoc-124-0652.pdf. Acesso em: 10/10/2016.

MORAIS, A.R.A. O preconceito contra os nordestinos nas redes sociais. In: LARA, G. M. P.; LIMBERTI, R. de C. P. (Org.). Representações do outro: discurso (des)igualdade e exclusão. 1. ed. Belo Horizonte, MG: Autêntica, 2016, pp. 260-75.

MORAIS, A.R.A. Reflexões sobre a intolerância política. Revista Interfacis, $\mathrm{n}^{\circ} 1$, v. 1. 2018, p. 40-6.

ORWELL, G. O que é fascismo? In: ORWELL, G. O que é Fascismo? e outros ensaios. São Paulo: Companhia das Letras, 2017.

OZ, A. Como curar um fanático: Israel e Palestina: entre o certo e o certo. São Paulo: Companhia das Letras, 2016.

PAXTON, R. O. A anatomia do fascismo. São Paulo: Paz e Terra, 2007.

PÊCHEUX, M. Semântica e discurso: uma crítica à afirmação do óbvio. Campinas: Editora da Unicamp, 2009. 
RANCIÈRE, J. A estética como política. Devires, Belo Horizonte, V. 7, N. 2, pp. 14-36, jul/dez. 2010.

Disponível

em: <http://www.fafich.ufmg.br/devires/index.php/Devires/article/view/325/186>. Acesso em: 10/01/2018.

RANCIÈRE, J. A partilha do sensível: estética e política. São Paulo: EXO experimental org.; Ed. 34, 2009.

SAFATLE, V. A esquerda que não teme dizer seu nome. São Paulo: Três Estrelas, 2012.

SERRANO, P. Autoritarismo e golpes na América Latina: breve ensaio sobre jurisdição e exceção. São Paulo: Editora Alameda, 2016.

SILVA, A. B.; BRITES, C. M.; OLIVEIRA, E. C. R; BORRI, G. T. A extrema-direita na atualidade. Serviço Social e Sociedade, n 119, pp. 407-45, jul./set. 2014. Disponível em: <http://www.scielo.br/scielo.php?script=sci_arttext\&pid=S0101-66282014000300002>. Acesso em: 01/08/2017.

VILLAZÓN, J. C. Velhas e novas direitas religiosas na América Latina: os evangélicos como fator político. In: CRUZ, S. V; KAYSEL, A.; CODAS, G. (orgs.). Direita, volver!: o retorno da Direita e o ciclo político brasileiro. São Paulo: Edição Fundação Perseu Abramo, 2015, pp. 163-75.

WITTGENSTEIN, L. Investigações Filosóficas. Coleção Os Pensadores. São Paulo: Editora Nova Cultural, 1999.

\section{MATÉRIAS DE SÍTIOS JORNALÍSTICOS}

ARANTES, P. E. Nova direita surgiu após junho, diz filósofo: depoimento. Entrevista concedida a Eleanora de Lucena. Folha de São Paulo, 31 de outubro 2014. Disponível em: <www1.folha.uol.com.br/poder/2014/10/1541085-nova-direita-surgiu-apos-junhodiz-filosofo.shtml>. Acesso em: 25 de abril de 2016.

BETTO, F. Por que fizemos opção pelos pobres (e eles pelo neopentecostalismo...)? Le Monde Diplomatique. Edição 113: 6 dezembro de 2016. Disponível em: $<$ http://diplomatique.org.br/por-que-fizemos-opcao-pelos-pobres-e-eles-peloneopentecostalismo/>. Acesso em: 01/08/2017.

JÚNIOR, C. A. C. Santander Cultural promove pedofilia, pornografia e arte profana em Porto Alegre. Locus Online, 06 de setembro de 2017, 8h21min. Disponível em: $<$ http://www.locusonline.com.br/2017/09/06/santander-cultural-promove-pedofiliapornografia-e-arte-profana-em-porto-alegre/>. Acesso em:01/01/2018.

CÂMARAMUNICIPAL. Vereadores manifestam repúdio a livro "Queermuseu". Câmara Municipal de Uruguaiana. 07/10/2017. Disponível em: $<$ http://uruguaiana.rs.leg.br/comunicacoes/noticias/vereadores-manifestam-repudio-alivro-201cqueermuseu201d>. Acesso em: 25/02/2018.

CHAUÍ, M. Sociedade brasileira: violência e autoritarismo por todos os lados: depoimento. Entrevista concedida a Juvenal Savian Filho e Laís Modelli. Revista Cult, 23 de fevereiro de 2016.2 Disponível em: $<$ www.revistacult.uol.com.br/home/2016/02/sociedade-brasileira-violencia-eautoritarismo-por-todos-os-lados >. Acesso em: 25 de abril de 2016. 
CASTELLS, M. Simpatia do brasileiro é um mito, diz sociólogo Manuel Castells: depoimento. Entrevista concedida a Sylvia Colombo. Folha de São Paulo. São Paulo: 18/05/2015. Disponível em: <http://www1.folha.uol.com.br/poder/2015/05/1630173internet-so-evidencia-violencia-social-brasileira-afirma-sociologo-espanhol.shtml $>$.

Acesso em: 28/01/2018.

NUNES, P. R. A Internet chegou para provar que somos um dos países mais racistas do mundo: depoimento. Entrevista concedida a María Martín. El País. Rio de Janeiro: 15/06/2016. Disponível em: <https://brasil.elpais.com/brasil/2016/05/10/politica/1462895132_579742.html>. Acesso em: 01/08/2017.

PINHEIRO-MACHADO, R. Nova direita conservadora não é burra: ela ataca o legado iluminista e o cerne da modernidade: depoimento. Carta Campinas, 11 de outubro de 2017. Disponível em: < http://cartacampinas.com.br/2017/10/nova-direita-conservadoranao-e-burra-ela-ataca-o-legado-iluminista-e-o-cerne-da-modernidade/ >. Acesso em: 11 de outubro de 2017.

RIBEIRO, R. J. Extrema-direita avança com ódio aos direitos humanos, diz filósofo: depoimento. Entrevista concedida a Roldão Arruda. Estadão, 14 de março de 2015. Disponível em: <http://politica.estadao.com.br/blogs/roldao-arruda/extrema-direitaavanca-com-odio-aos-direitos-humanos-diz-filosofo//.> Acesso em: 25/04/2016.

SANTOS, R. Exposição fechada mostra que brasileiro não é mais cordeirinho. Folha de São Paulo. 12 de setembro de 2017. Disponível em: <http://www1.folha.uol.com.br/ilustrada/2017/09/1917634-exposicao-fechada-mostraque-brasileiro-nao-e-mais-cordeirinho.shtml>. Acesso em: 10/01/2018.

\section{PESQUISAS DE OPINIÃO}

CQM. Dossiê Intolerâncias Visíveis e Invisíveis no mundo digital. Agência Nova S/B. São Paulo: 2016. Disponível em: $<$ http://www.comunicaquemuda.com.br/dossie/intolerancia-nas-redes/>. Acesso em: $01 / 10 / 2017$.

FBSP. $9^{\circ}$ Anuário Brasileiro de Segurança Pública. São Paulo: 2015. Disponível em: <http://www.forumseguranca.org.br/atividades/anuario/>. Acesso em: 01/10/2017.

FBSP. Medo da Violência e o apoio ao autoritarismo no Brasil: Índice de Propensão ao apoio a posições autoritárias. São Paulo: 2017. Disponível em: <http://www.forumseguranca.org.br/atividades/anuario/>. Acesso em: 01/10/2017.

INSTITUTOPARANÁ. Consulta sobre Regime Militar no Brasil. Curitiba: 2017. Disponível em: <http://www.paranapesquisas.com.br/pesquisas/pesquisa-brasil-onlineregime-militar-no-brasil-setembro-2017/>. Acesso em: 01/10/2017.

Data de Recebimento: 15/02/2018

Data de Aprovação: 07/06/2018 


\section{Para citar essa obra:}

MORAIS, Argus Romero Abreu. A estética da intolerância: extremismo político e arte no Brasil atual. In: RUA [online]. Volume 24, número 2 - p. 499-524 - e-ISSN 21799911 - novembro/2018. Consultada no Portal Labeurb - Revista do Laboratório de Estudos Urbanos do Núcleo de Desenvolvimento da Criatividade.

http://www.labeurb.unicamp.br/rua/

Capa: foto QueerMuseu. Disponível em https://goo.gl/7xTBBH

\section{Laboratório de Estudos Urbanos - LABEURB}

Núcleo de Desenvolvimento da Criatividade - NUDECRI

Universidade Estadual de Campinas - UNICAMP

http://www.labeurb.unicamp.br/

\section{Endereço:}

LABEURB - LABORATÓRIO DE ESTUDOS URBANOS

UNICAMP/COCEN / NUDECRI

CAIXA POSTAL 6166

Campinas/SP - Brasil

CEP 13083-892

Fone/ Fax: (19) 3521-7900

Contato: http://www.labeurb.unicamp.br/contato 